\title{
A IMPORTÂNCIA DA GESTÃO DE ESTOQUES NAS ORGANIZAÇÕES CONTEMPORÂNEAS
}

\author{
Geisiane dos Santos Araújo ${ }^{1}$, Paulo Roberto Rosa ${ }^{2}$ \\ ${ }^{1}$ Universidade do Oeste Paulista - UNOESTE, Pós - Graduação em Avaliação do Ensino e da Aprendizagem, Presidente \\ Prudente - SP. ${ }^{2}$ Instituto Federal de São Paulo - IFSP, Presidente Epitácio - SP e Universidade do Oeste Paulista - \\ UNOESTE, Mestrado em Meio Ambiente e Desenvolvimento Regional, Presidente Prudente - SP. E-mail: \\ geisisantos2@gmail.com
}

\section{RESUMO}

O crescimento econômico e a internacionalização dos negócios acirram de tal forma a competição, que agora acontece em escala global, que a concorrência atualmente não se dá mais de forma individual, empresa contra empresa. A competição atualmente está estabelecida e acontece entre cadeias produtivas como um todo. Uma boa gestão de estoques deve responder a questionamentos como: O que e quanto os clientes compram? Quais os insumos necessários? Qual o nível de estoque? Qual o custo desse estoque? Pretende-se com este trabalho demonstrar o quão importante é uma boa gestão de estoques nas organizações contemporâneas, ou seja, demonstrar que a gestão de estoques quando bem conduzida pode auxiliar ou até mesmo levar uma empresa a conquista da tão sonhada vantagem competitiva. Em sua vertente teórica esse trabalho classifica-se como bibliográfico de caráter qualitativo e, ao buscar solução para problemas específicos em uma determinada área do conhecimento, enquadra-se como pesquisa aplicada.

Palavras-chave: Negócios. Competição. Estoques. Insumos. Vantagem Competitiva.

\section{THE IMPORTANCE OF STOCKING MANAGEMENT IN TODAY'S CORPORATIONS}

\begin{abstract}
The economical growth and the internationalization of business harden competition so much, that now happens in a global scale, that it is not in an individual basis, company versus company. Competition now is established and happens among productive chains as a whole. A good supply management must attend to questions, such as: What and how much the customers buy? What are the necessary inputs? What are their levels of stock? What is the cost of these supplies? The intention of this work is to demonstrate that the supplies management, when is well directed can help or even take a company to the achievement of the dreamt competitive advantage. In a theorical versant, this work is classified as bibliographic of a qualitative character and to seek solutions to specific in a given area of knowledge problems, is classified as applied research.
\end{abstract}

Keywords: Business. Competition. Supplies. Inputs. Competitive Advantage. 


\section{INTRODUÇÃO.}

A constituição de estoques é inerente a existência humana desde o princípio e sua importância cresce a cada dia que passa. Na antiguidade havia a preocupação do homem no que se refere a ir em busca dos mantimentos necessários a sua sobrevivência, seja através da caça ou outro método que pudesse Ihe proporcionar a subsistência. Esse material, quando não consumido prontamente, é trabalhado para que possa ser armazenado e utilizado no futuro. Os métodos e técnicas de armazenamento e movimentação vão sendo aperfeiçoados pelo homem com vistas ao prolongamento da vida útil e a manutenção da qualidade dos materiais armazenados, sempre com o objetivo de atender às necessidades organizacionais e humanas em constante evolução.

Com o crescimento dos mercados e a internacionalização dos negócios, a concorrência aumentou consideravelmente a complexidade no mundo dos negócios e a competição passou a ser entre cadeias produtivas. Os estoques passaram a desempenhar um papel fundamental na composição dos custos operacionais e no desempenho atingido pelas empresas. Com o uso de recursos computacionais buscou-se a integração de operações e informações ao longo da cadeia, o que permitiu a redução dos níveis de estoque e dos custos envolvidos. As organizações precisam de estoque para atender às necessidades dos seus clientes, mas o devem fazer de modo a minimizar o aporte financeiro e ao mesmo tempo elevar o índice de rotatividade dos estoques. Ou seja, estoques menores com um giro maior no período, mais negócios realizados com o mesmo volume de mercadorias em estoque.

Pretende-se aqui demonstrar o quão importante é uma boa gestão de estoques nas organizações contemporâneas, ou seja, demonstrar que a gestão de estoques quando bem conduzida pode auxiliar ou até mesmo levar uma empresa a conquista da tão sonhada vantagem competitiva.

\section{METODOLOGIA}

Para realização do escopo a que se propõe este trabalho foi realizada uma pesquisa bibliográfica amparada em obras de renomados autores. Na busca por aproximar da realidade as reflexões teóricas aqui conduzidas, foi também realizado o estudo de um caso prático de estoques em uma empresa da região.

\section{ESTOQUES.}

O conceito de estoque está relacionado a bens ou produtos que uma organização mantém para atender a uma determinada demanda futura. Segundo Slack et al (1996, p. 381) "estoque é 
definido aqui como a acumulação armazenada de recursos materiais em um sistema de transformação". Para Chiavenato $(2005$, p. 67) "o estoque constitui todo o sortimento de materiais que a empresa possui e utiliza no processo de produção de seus produtos/serviços". Como se pode observar estoque é muito mais que a matéria prima adquirida, produto acabado resultante do processo de transformação ou mercadoria adquirida para fins de comercialização. Sob a ótica de Francischini e Gurgel (2004, p. 81) "define-se estoque como quaisquer quantidades de bens físicos que sejam conservados, de forma improdutiva, por algum intervalo de tempo". Arnold (1999) destaca que:

Os estoques são materiais e suprimentos que uma empresa ou instituição mantém, seja para vender ou para fornecer insumos ou suprimentos para o processo de produção. Todas as empresas e instituições precisam manter estoques. Freqüentemente, os estoques constituem uma parte substancial dos ativos totais (ARNOLD, 1999, p. 265).

Como destacado por Arnold (1999), é comum as empresas terem uma grande quantidade de capital investido em estoques, os quais muitas vezes não geram à empresa o retorno esperado. "Espera-se, então, que o dinheiro investido em estoques seja o lubrificante necessário para a produção e o bom atendimento das vendas" (DIAS, 1993, p. 23). É no estoque que muitas vezes está o segredo para o sucesso, onde se poderá encontrar o caminho para uma redução dos custos sem que isso resulte em queda no volume de negócios, redução nos níveis de qualidade e/ou insatisfação dos clientes.

Por permear as várias fases dos processos de compra e venda, acrescido da transformação no caso de empresas industriais, já é possível presumir então a existência de diversos tipos ou modalidades de estoque conforme a etapa desses processos. Esses estoques podem ser classificados de diversas formas, conforme o ponto de vista e interpretação do autor. Chiavenato (2005) disciplina que:

Os estoques podem ser classificados de acordo com os mesmos critérios de classificação de materiais:

1. Estoques de matérias-primas (MPs).

2. Estoques de materiais em processamento (ou em vias).

3. Estoques de materiais semi-acabados.

4. Estoques de materiais acabados (ou componentes).

5. Estoques de produtos acabados (PAs).

(CHIAVENATO, 2005, p. 69)

Já Francischini e Gurgel (2004) classificam os estoques em quatro categorias:

- Estoques de matérias-primas - materiais e componentes comprados de fornecedores, armazenados na empresa compradora e que não sofreram nenhum tipo de processamento. 
- Estoques de materiais em processo - materiais e componentes que sofreram pelo menos um processamento no processo produtivo da empresa compradora e aguardam utilização posterior.

- Estoque de produtos auxiliares - peças de reposição, materiais de limpeza, materiais de escritório, etc.

- Estoque de produtos acabados - produtos prontos para comercialização.

(FRANCISCHINI \& GURGEL, 2004, p. 81, Grifo no original).

Para Pozo (2004, p. 41) uma empresa possui até cinco tipos de estoque: matérias primas, materiais auxiliares, manutenção, intermediário e acabados. Dias (1993, p. 29-30) considera que "os principais tipos de estoque encontrados em uma empresa industrial são: matérias-primas, produtos em processo, produtos acabados, e peças de manutenção". Os autores citados utilizamse de nomenclaturas diferentes para referir-se as mesmas coisas, as vezes agrupando alguns gêneros e as vezes desdobrando-os.

Para que os estoques se tornem um elemento agregador de valor e uma fonte de vantagem competitiva eles necessitam de uma gestão que prime pela excelência, que seja ao mesmo tempo eficiente e eficaz na conquista dos objetivos. A importância dos estoques se estende a todas as empresas, independentemente do ramo de negócio toda empresa terá de constituir estoques, mesmo que seja para materiais de uso e consumo. Para Carretoni (2000, p. 83) gestão de estoques "significa gerir, administrar e racionalizar com economia os diferentes tipos de estoques mantidos pela organização", e destaca alguns pontos que a tornam importante: a) crescimento e desenvolvimento econômico, aumenta a demanda por bens e serviços; b) escassez de capital e a necessidade de aproveitar oportunidades, inclusive redução de custos; c) necessidade de investimentos em pesquisa e desenvolvimento; $d$ ) introdução de novas metodologias, estilos e sistemas gerenciais; e) expansão e internacionalização dos negócios; f) concorrência a nível global; e g) importância da função materiais na cadeia produtiva.

Como destaca Carretoni (2000), a gestão de estoques torna-se relevante e necessária por diversos fatores, dentre os quais o alto valor comumente investido, a necessidade de dimensionar estoques adequado, evitar faltas ou estoques excedentes, garantir a qualidade e a integridade dos materiais, etc. Para Dias (1993, p. 23) "o objetivo, portanto, é otimizar o investimento em estoques, aumentando o uso eficiente dos meios internos da empresa, minimizando as necessidades de capital investido". Para Dias (1993), as principais atribuições da gestão de estoques são:

a) determinar "o quê" deve permanecer em estoque. Número de itens;

b) determinar "quando" se devem reabastecer os estoques. Periodicidades; 
c) determinar "quanto" de estoque será necessário para um período predeterminado;

d) acionar o Departamento de Compras para executar aquisição de estoques;

e) receber, armazenar e atender os materiais estocados de acordo com as necessidades;

f) controlar os estoques em termos de quantidade e valor e fornecer informações sobre a posição do estoque;

g) manter inventários periódicos para avaliação das quantidades e estados dos materiais estocados; e

h) identificar e retirar do estoque os itens obsoletos e danificados.

(DIAS, 1993, p. 29).

As técnicas, práticas ou ferramentas utilizadas na gestão de estoque estão associadas ao dimensionamento e a valorização dos estoques. No que se refere ao dimensionamento dos estoques podemos elencar os métodos estatísticos do último período, da média móvel e da média móvel ponderada. Na valorização dos estoques podem ser empregadas as metodologias do custo médio, custo de reposição, primeiro que entra primeiro que sai (PEPS) e último que entra primeiro que sai (UEPS). Uma boa gestão de estoques deve também estar atenta aos custos envolvidos na estocagem e que são os custos de aquisição, armazenagem, pedido, falta e capacidade.

\section{ESTUDO DE CASO.}

O presente estudo buscou estabelecer uma conexão entre o conhecimento aqui tratado e a realidade ou prática em uma determinada empresa. Para isso, foi escolhida a empresa Regina Indústria e Comércio S/A, uma planta industrial localizada na cidade de Bataguassu/MS. Os armazéns da empresa são subdivididos em corredores, o que leva a gestão de estoques possuir a seguinte estrutura operacional de pessoas: um líder, um conferente e um auxiliar, responsáveis pelo estoque físico de cada corredor. É possível perceber claramente que a empresa possui processos bem definidos e que lhe garantem um bom desempenho na gestão dos estoques.

Para que haja o recebimento de mercadorias faz-se necessário um agendamento prévio. Um veículo, ao chegar para realizar uma entrega, faz-se uma verificação inicial se há o agendamento e o veículo é então direcionado para uma doca onde será realizado a conferência e o desembarque. O desembarque é feito com a utilização de equipamentos para movimentação de materiais, o que pode se dar mediante uso de carrinhos paleteiros manuais, elétricos e empilhadeiras em casos específicos. Uma vez feito o desembarque é realizada uma conferência 
cega $^{1}$ e caso existam divergências realiza-se uma nova verificação. Em seguida é realizada uma inspeção de caráter qualitativo, para verificar se o material entregue atende aos requisitos previamente acordados junto ao fornecedor. Em confirmada alguma não conformidade o caso é repassado ao departamento de compras para que entre em contato com o fornecedor para dirimir quaisquer dúvidas, negociar e/ou resolver o problema, o que poderá se dar mediante devolução, complementação ou correção da não conformidade. Em todos os casos é realizado o bloqueio até que o problema seja definitivamente resolvido e o material é segregado ${ }^{2}$ em depósito específico.

Vencida essa primeira etapa a nota fiscal é lançada para fins contábeis no Sistema Integrado de Gestão (ERP) utilizado pela empresa. O material é então liberado para ser movimentado para posição pallet ${ }^{3}$ que estiver disponível, o qual é identificado com o código e quantidade, em seguida armazenada pelas empilhadeiras e apontado para o controle de estoque lançar no sistema. Vale destacar que, dada a diversidade de produtos estocados e de suas respectivas dimensões, há situações em que uma posição pallet abriga mais de um tipo de produto.

Uma vez recebidos os materiais são endereçados para estocagem. Quando o material chega até o departamento de controle de estoque é efetuado o lançamento no sistema seguindo a ordem depósito, corredor, posição, código e quantidade. Já existe no sistema o registro de todas as posições disponíveis no armazém para que sejam então endereçados e direcionados materiais para armazenamento.

A programação da necessidade de matéria prima e embalagem obedece ao Planejamento e Controle de Produção (PCP) realizado semanalmente pelas fábricas. Dado a existência de agentes embaladores contratados externamente, a programação para estes é realizada diariamente, conforme a demanda. A separação das matérias primas e embalagens é realizada manualmente com o uso de carrinhos paleteiros e/ou empilhadeiras, sempre em obediência as ordens de produção (OP), com as perdas e danos a partir deste ponto sob responsabilidade do departamento de PCP.

No que se refere a custo dos materiais, o controle segue o que disciplina a Receita Federal, ou seja, o custo médio, o que implica na não utilização dos métodos de avaliação de estoques PEPS/FIFO e UEPS/LIFO. As matérias-primas e/ou materiais de embalagem utilizados não possuem tempo de validade definido, sendo este um facilitador no processo de estocagem.

\footnotetext{
${ }^{1}$ Conferência cega: o lançamento é realizado mediante uso apenas do documento fiscal ou de movimentação, sem uma conferência física do material, com a não conformidade apontada pelo confronto com o pedido de compra ou ordem de produção.

${ }^{2}$ Segregado: separado, colocado a parte.

${ }^{3}$ Pallet: estrado de madeira para acondicionamento de materiais. 
Os estoques da empresa são separados em dois grandes grupos: matérias-primas (inclusive embalagens) e produtos acabados. Na mesma linha das matérias-primas e embalagens, os produtos acabados são recebidos para estocagem também mediante uma conferencia cega. 0 endereçamento dos produtos acabados para as áreas de estoque também não é automática, é realizada de acordo com as áreas disponíveis e apontadas no sistema. A empresa faz a gestão dos estoques sempre com base no estoque real, o que implica na não utilização de modelos de gestão baseados em estoque médio. No que se refere ao emprego de estoque de segurança ele se dá mediante um cálculo realizado com base na estimativa de vendas o que, para a maioria dos produtos, toma-se por base um espaço temporal de 10 dias.

O inventário de estoque é realizado diariamente através de uma contagem cíclica com o uso de curva $A B C$. Para efeitos de fechamento contábil é realizado também um inventário anual. Caso haja alguma divergência quanto a localização dos produtos que consta no sistema, realiza-se uma ampla pesquisa das movimentações realizadas e, caso necessário, faz-se uma verificação in loco. Constatado irregularidade ao se confrontar os registros de estoque ao físico, é solicitado um ajuste que somente será efetuado após uma minuciosa análise e liberação por auditoria externa realizada anualmente.

A preparação e separação dos pedidos, também conhecida como picking, é realizada através do recurso responsável pelo corredor, preferencialmente ao início de cada expediente. No entanto, caso necessário, pode ocorrer também normalmente durante o expediente. A separação dos pedidos é realizada através de mapas de separação que agrupam todos os itens armazenados em determinado corredor. Atualmente a empresa não possui uma medição da capacidade de separação de pedidos por colaborador e/ou corredor, apenas uma capacidade máxima da planta que gira em torno de $\mathrm{R} \$ 1.500 .000,00$ (um milhão e quinhentos mil reais) dia.

A destinação do checkout é feita pelo líder do setor e a movimentação é realizada mediante o uso de carrinhos paleteiros. Caso ao chegar ao checkout seja constatada alguma não conformidade o colaborador que realizou a separação é contatado, orientado e a correção providenciada. Para evitar o envio de pedidos com falta ou sobra de produtos é realizado um confronto entre o pedido do cliente e o material que está sendo separado, com uma verificação amostral pelo controle de qualidade. A produtividade diária de cada checkout varia de acordo com o produto, mas está entre 50 e $100 \mathrm{~kg}$ dia.

A empresa atende a clientes em todo o Brasil e, para isso, conta atualmente com um Centro de Distribuição (CD) medindo 13.468 m2 e 15.690 posições pallet. Com vistas a promover uma melhoria contínua nos processos relacionados a estoques, a empresa opera com alguns 
indicadores de performance, dentre os quais se destacam: a) número de pedidos atendidos em até 24 horas; b) sobra ou falta de mercadorias no checkout; c) percentual de acurácia nos estoques; e $d$ ) percentual de entregas realizadas pelos fornecedores dentro do lead time.

\section{CONSIDERAÇÕES FINAIS.}

O estoque é um ativo organizacional que permanece improdutivo até que seja utilizado. Portanto, é fundamental que o prazo decorrido entre o aporte de investimento nesses materiais que permanecerão estagnados na empresa e a sua aplicação definitiva deve ser o mais curto possível, para que assim possa retornar ao caixa da empresa mediante o faturamento do produto acabado. Com a manutenção de mercadorias no estoque a empresa incorre em uma série de custos que vão além do simples valor pago pela mercadoria ao fornecedor, passa pelos custos de armazenagem, pedido e capacidade. A ausência de estoque também impõe a empresa custos relacionados a uma linha de produção parada, uma venda perdida, um cliente insatisfeito, etc.

Assim, é possível compreender a importância estratégica dos estoques e a necessidade de uma gestão que prime pela excelência na condução deste ativo organizacional. Gerir estoques é uma atividade complexa, lida com fatores endógenos e exógenos, a montante e a jusante, e que nem sempre a empresa tem controle absoluto. Essa complexidade é proporcional ao tamanho da empresa e a participação no mercado, quanto maiores forem esses elementos maior será o desafio para se alcançar um estoque equilibrado, que atenda as expectativas da empresa e dos clientes, sem deixar faltar mercadoria e ao mesmo tempo sem elevar o valor dos estoques.

Uma boa compreensão da demanda associada a um bom dimensionamento dos estoques, sejam eles de matérias primas, embalagens ou produtos acabados, desempenham papel fundamental no atendimento às necessidades do negócio. Um bom entendimento do ambiente de negócios tem propiciado à Regina Indústria e Comércio S/A a manutenção de níveis de estoque adequados, que não comprometem a sua capacidade de atender aos seus clientes e tampouco a capacidade de realizar novos investimentos.

\section{REFERÊNCIAS}

ARNOLD, J. R. Tony. Administração de Materiais: uma introdução. São Paulo: Atlas, 1999.

CARRETONI, Enio. Administração de Materiais: uma abordagem estrutural. Campinas: Alínea, 2000.

CHIAVENATO, Idalberto. Administração de Materiais: uma abordagem introdutória. Rio de Janeiro: Elsevier, 2005. 
DIAS, Marco A. P. Administração de Materiais: uma abordagem logística. 4a ed. São Paulo: Atlas, 1993.

FRANCISCHINI, Paulino G.; GURGEL, Floriano do A. Administração de Materiais e do Patrimônio. São Paulo: Pioneira Thomson Learning, 2004.

MARTINS, Petrônio G.; ALT, Paulo R. C. Administração de Materiais e Recursos Patrimoniais. $3^{\mathrm{a}}$ ed. São Paulo: Saraiva, 2009.

POZO, Hamilton. Administração de Recursos Materiais e Patrimoniais: uma abordagem logística. $3^{a}$ ed. São Paulo: Atlas, 2004. 